\title{
PENGUATAN MANAJEMEN MODAL KERJA SEBAGAI KELANGSUNGAN START-UP KAWASAN UNNES
}

\author{
Ita Nuryana $^{1)}$, Margunani ${ }^{2}$, Suwito Eko Pramono ${ }^{3)}$ \\ Program Studi Pendidikan Akuntansi, Jurusan Pendidikan Ekonomi, Universitas Negeri Semarang ${ }^{12)}$, \\ Fakultas Ilmu Sosial, Universitas Negeri Semarang ${ }^{3)}$ \\ ita.nuryana@mail.unnes.ac.id ${ }^{1)}, \underline{\text { margunani@mail.unnes.ac.id }}{ }^{2)}, \underline{\text { suwitoekop@mail.unnes.ac.id }}^{3)}$
}

\begin{abstract}
Lack of knowledge about working capital management caused the sustainability of start-ups in UNNES area is still being low. It resulted that manager of start-ups are difficult to develop themselves. Therefore, it need for training to improve the skills in making good financial, so the sustainability of start-ups is reached. To increase of the existence and sustainability of start-ups are also required the reinforcement of working capital management by manager of the start-up. Then, focus of devotion is the owner and manager of the start-ups in UNNES area that gathered in HIPMI PT UNNES. Purpose of this devotion is improving and making good working capital management for the sustainability of start-up. Participants in this devotion 25 people. Procedure in this devotion is carried out by delivering of material on working capital management. In supporting of devotion, the dedication team arranges the module of working capital management. Outcome of this devotion is creating that the manger of the start-up can continue their start-up, so it can reduce the number of unemployment.
\end{abstract}

Keywords: Working Capital Management, Start-Up, Commitment Of Entrepreneurship

\begin{abstract}
Abstrak
Minimnya pengetahuan mengenai manajemen modal kerja menyebabkan keberlangsungan start-up di kawasan UNNES menjadi rendah. Hal tersebut mengakibatkan pelaku dan pengurus start-up sulit untuk mengembangkan diri. Oleh karena itu, perlu adanya pelatihan untuk peningkatan keterampilan pembuatan laporan keuangan yang baik sehingga keberlangsungan start-up tercapai. Untuk meningkatkan eksistensi dan keberlangsungan start-up juga diperlukan adanya penguatan manajemen modal kerja yang dimiliki oleh pelaku start-up. Maka, fokus pengabdian adalah para pemilik dan pengurus start-up di kawasan UNNES yang terhimpun dalam HIPMI PT UNNES. Tujuan dari pelaksanaan pengabdian kepada masyarakat ini adalah agar pemilik dapat melakukan manajemen modal kerja dengan baik untuk keberlangsungan start-up. Peserta kegiatan ini adalah pemilik dan pengelola Start-Up yang berjumlah sekitar 25 orang. Prosedur pelaksanaan pengabdian kepada masyarakat dilakukan dengan penyampaian materi tentang manajemen modal kerja. Dalam mendukung kegiatan ini, tim pengabdian melakukan penyusunan modul Manajemen Modal Kerja. Luaran dari pelaksanaan pengabdian kepada masyarakat ini yaitu pemilik dan pengurus Start-Up tetap mempertahankan keberlangsungan start-up sehingga dapat mengurangi jumlah pengangguran.
\end{abstract}

Kata kunci: Manajemen Modal Kerja, Start-up, Komitmen Berwirausaha 


\section{PENDAHULUAN}

Data BPS menyebutkan pertumbuhan ekonomi Indonesia pada kuartal III- 2017 naik 0,05 persen menjadi 5,06 persen, dibandingkan pertumbuhan pada kuartal sebelumnya. Hal tersebut menunjukkan bahwa pertumbuhan ekonomi Indonesia tidak berkualitas. Seharusnya setiap sekian persen pertumbuhan mampu menciptakan tambahan lapangan kerja atau mengurangi pengangguran.

"Pertumbuhan berkualitas berarti mengurangi pengangguran, ketimpangan dan kemiskinan, itu kualitas. Tapi kalau pertumbuhan tinggi, pengangguran masih banyak, kemiskinan tinggi, berarti tidak ada kualitasnya pertumbuhan ekonomi kita," (Koran Jakarta, 2017). Laporan Badan Pusat Statistik (BPS) tahun 2017 menunjukkan bahwa jumlah penganggur di Indonesia menurut tingkat pendidikan tertinggi yang ditamatkan disajikan dalam gambar 1 .

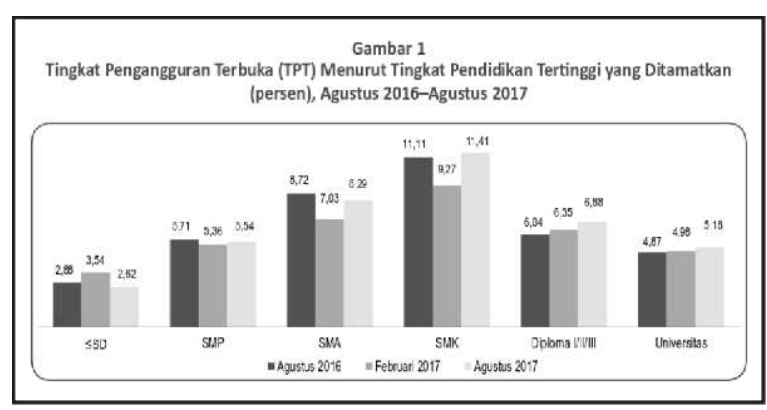

Sumber: BPS Tahun 2017

Berdasarkan data tersebut, tingkat pengangguran terbuka tertinggi dari Agustus 2016 sampai dengan Agustus 2017 adalah lulusan SMK. Universitas sebagai jenjang pendidikan tertinggi diharapkan dapat menciptakan lapangan pekerjaan baru, namun fakta dilapangan jumlah penganggur dari lulusan universitas cukup tinggi. Gambar di atas menunjukkan pada Agustus 2017 tingkat pengangguran dari lulusan universitas mencapai 5,18\%. Dengan demikian ada kenaikan jumlah penganggur lulusan universitas jika dilihat dari data bulan Agustus 2016 sebesar 4,87\% dan Februari 2017 sebesar 4,98\%.
Tingginya tingkat pengangguran terbuka lulusan universitas sangatlah disayangkan. Perguruan tinggi harus melakukan evaluasi dan inovasi untuk mengurangi jumlah lulusan sarjana yang menganggur tersebut untuk dapat kembali pada tujuan utamanya yaitu menghasilkan lulusan yang menguasai cabang ilmu pengetahuan dan/atau teknologi untuk memenuhi kepentingan nasional dan peningkatan daya saing bangsa (nation competitiveness) dengan mengembangkan potensi mahasiswa agar menjadi manusia yang beriman dan bertakwa kepada Tuhan Yang Maha Esa dan berakhlak mulia, sehat, berilmu, cakap, kreatif, mandiri, terampil, kompeten, dan berbudaya untuk kepentingan diri sendiri, masyarakat, bangsa, dan negara (pasal 5 UU No.12 tahun 2012).

Universitas Negeri Semarang sebagai universitas yang berwawasan konservasi dan bereputasi internasional berusaha mencapai tujuan perguruan tinggi yang tercantum dalam Undang-Undang tersebut dengan pengoptimalan kegiatan konservasi, yaitu melestarikan, melindungi dan mengawetkan sumber daya yang ada di sekitarnya (Peraturan Rektor Universitas Negeri Semarang Nomor 27 Tahun 2012 Tentang Tata Kelola Kampus Berbasis Konservasi di Universitas Negeri Semarang).

Salah satu upaya yang diterapkan UNNES di dalam menerapkan konsep konservasi adalah melalui program kewirausahaan. Mahasiswa yang memiliki jiwa dan komitmen untuk mandiri dengan berwirausaha dapat dilihat dari usahanya untuk memulai usaha baru. Tahapan pertama pendirian usaha tersebut sampai dengan fase perkembangan dan penelitian untuk menemukan pasar yang tepat dikenal dengan istilah start-up.

Salah satu aspek penting yang harus dipahami start-up dengan usaha yang mereka jalankan adalah bagaimana mengelola sistem 
modal kerja dengan tepat. Modal kerja selalu menempati posisi penting dalam menjaga kelangsungan usaha. Modal kerja pada dasarnya merupakan nilai uang yang melalui arus kas. Nilai yang akan perusahaan hasilkan dan keluar untuk operasi perusahaan.

Hal tersebut di atas sejalan dengan hasil penelitian Margunani 2015, Mahasiswa yang telah memulai usaha baru, dan masih bertahan dalam 1-2 tahun menunjukkan bahwa gigihnya mereka dalam menjalankan usaha, pantang menyerah untuk menjadi wirausaha yang berhasil. Kendala yang dihadapi mahasiswa pelaku usaha baru, pada umumnya adalah keterbatasan (minimnya) modal kerja yang harus diputar dalam melaksanakan usaha; gagalnya usaha perdana, sehingga mereka berkreasi untuk menambah dan atau mengganti usaha yang masih berhubungan dengan usaha semula

Salah satu cara efektif untuk memudahkan perusahaan mengelola sistem modal kerja adalah dengan menyusun siklus operasi. Siklus operasi pada dasarnya adalah penentuan jadwal dan durasi bagaimana operasional usaha berjalan. Siklus ini berkaitan dengan periode produksi, besaran produksi, jadwal dan biaya yang harus dikeluarkan per produksi.

Universitas Negeri Semarang (UNNES) berperan aktif dalam program PMW dari tahun 2009 sampai dengan tahun 2013 didampingi dosen pembimbing di bawah koordinasi bidang kemahasiswaan. Tujuan Program Mahasiswa Wirausaha (PMW) Unnes:

(1) Menumbuhkembangkan wirausahawirausaha baru yang berpendidikan tinggi;

(2) Mendorong terbentuknya model pendidikan kewirausahaan di UNNES; dan

(3) Mendorong pertumbuhan dan perkembangan kelembagaan pengelola kewirausahaan mahasiswa di UNNES.

Cooperative Academic Education
Program (COOP) telah dilaksanakan oleh Unnes tahun 2008 dengan 8 peserta yang lolos seleksi dan 4 Usaha Kecil dan Menengah (UKM) Mitra, tahun 2009 ada 10 peserta yang lolos seleksi dan 6 Usaha Kecil dan Menengah (UKM) Mitra, dan tahun 2010 terdapat 12 peserta yang lolos seleksi dan 8 Usaha Kecil dan Menengah (UKM).

Pada tahun 2012 bekerjasama dengan Bank Indonesia dilakukan pembekalan kepada 15 mahasiswa terpilih yang benarbenar berminat menjadi wirausahawan. Guna menunjang pelaksanaan kegiatan programprogram tersebut, Universitas Negeri Semarang telah kerjasama dengan beberapa UKM, Bank Indonesia maupun bank umum (BRI, BNI, Bank mandiri), CV Permodalan Java Ventura Jawa Tengah dan lain-lain.

Produk PKMK sudah siap dilaunching untuk dipromosikan, namun mahasiswa terbentur pada ketersediaan dana untuk menindaklanjuti. Produk yang berpotensi ini, antara lain: Susu umbi bengkuang; Yogurt jagung sehat dan berenergi; Sirup pisang; Briket ampas tebu ramah lingkungan; Krupuk sehat buah pare penurun gula darah; Permen dengan bahan dasar buah naga; Krim anti nyamuk dari kulit buah jeruk. Serbuk kayu menjadi kotak pensil, biscuit ubi ungu, Sirup salam alternatif obat diabetes, audio frekuensi pengusir tikus, dll.

Berdasarkan hasil workshop pengelolaan pengelolaan usaha produk PKM-K (5 Mei 2012) mahasiswa pelaku program kewirausahaan yang sudah lulus, masih menjalankan usahanya. Terdapat alumni dengan usaha yang sama dengan usaha awal, ada yang ganti, ada yang berkembang dengan menambah usaha lain. Melihat antusias mahasiswa Unnes, kebutuhan stakeholder internal maupun eksternal, tanggal 10 Oktober 2010 telah dilaunching Pusat kewirausahaan mahasiswa di Unnes dengan nama "Unnes Student Entrepreneurship Center (UNSEC)". Mahasiswa yang telah 
berwirausaha bertugas untuk menceritakan tahapan-tahapan berwirausaha yang telah dilaluinya hingga bisnis yang dijalankannya dapat bertahan dan bahkan berkembang melalui sesi success story.

\section{METODE PENELITIAN}

Untuk memberikan pelatihan dalam penguatan manajemen modal kerja sebagai upaya keberlangsungan start-up di kawasan UNNES digunakan metode ceramah dan praktik. Metode ceramah digunakan untuk menyampaikan materi atau teori yang berkaitan dengan manajemen modal kerja. Setelah peserta menerima penjelasan mengenai tata cara pencatatan siklus kas, pencatatan siklus persediaan, dan pencatatan siklus piutang yang baik dan benar, peserta diberikan kesempatan untuk mempraktikkannya dengan membuat laporan siklus kas, persediaan, dan piutang. Untuk mengidentifikasi keberhasilan peserta pelatihan manajemen modal kerja digunakan metode diskusi.

Berdasarkan paparan di atas, berikut ini Road Map dalam pelaksanaan pengabdian kepada masyarakat:

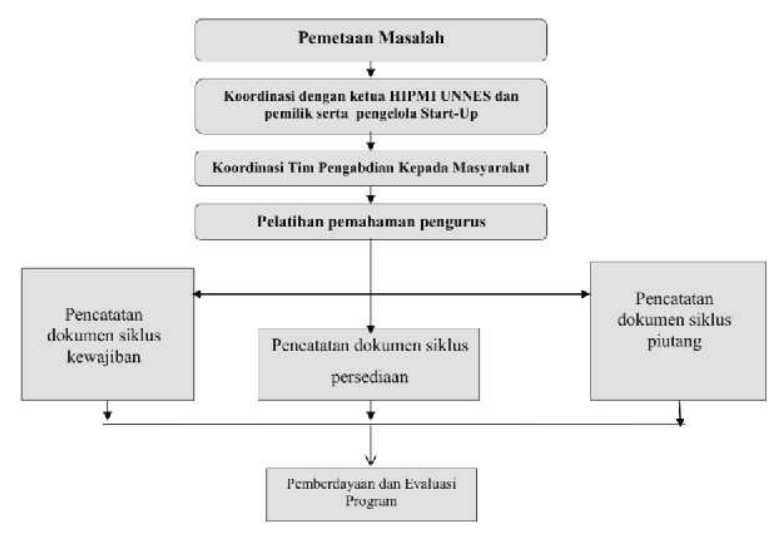

\section{HASIL DAN PEMBAHASAN}

Kegiatan pengabdian kepada masyarakat di kawasan UNNES dilaksanakan pada bulan Juli 2018 di Semarang.

Kegiatan yang dilaksanakan meliputi pelatihan mengenai manajemen modal kerja. Kegiatan pelatihan manajemen modal kerja yang baik dilakukan melalui tahapan sebagai berikut:

\section{Tabel 1. Kegiatan Pelatihan Penguatan Manajemen Modal}

\begin{tabular}{|c|c|c|c|}
\hline Tahap & Kegiatan & Tujuan & Hasil \\
\hline 1. & $\begin{array}{l}\text { Koordinasi dengan ketua } \\
\text { HIPMI PT UNNES dan } \\
\text { pemilik serta pengelola } \\
\text { Start-Up }\end{array}$ & \begin{tabular}{|l|} 
Menyamakan persepsi \\
tujuan pengabdian \\
kepada masyarakat yang \\
akan dilakukan Tim \\
Pengabdian
\end{tabular} & $\begin{array}{l}\text { a. Pemclaan prioritas } \\
\text { permasalahan yang } \\
\text { dihadapi Start-Up } \\
\text { b. Menentukan alternatif } \\
\text { pemecahan masalah } \\
\text { Manajemen Modal } \\
\text { Kerja }\end{array}$ \\
\hline 2. & $\begin{array}{l}\text { Koordinasi Tim Pengabdian } \\
\text { Kepada Masyarakat }\end{array}$ & $\begin{array}{l}\text { a Melakukan pemetaan } \\
\text { prioritas } \\
\text { permasalahan } \\
\text { b Memilih alternatif } \\
\text { permasalahan }\end{array}$ & $\begin{array}{l}\text { Draf modul Manajemen } \\
\text { Modal Kerja bagi Start- } \\
\text { Up }\end{array}$ \\
\hline 3. & $\begin{array}{l}\text { Koordinasi dengan ketua } \\
\text { HIPMI UNNES dan } \\
\text { pemilik serta pengelola } \\
\text { Start-Up }\end{array}$ & \begin{tabular}{|l|} 
Menentukan pelaksanaan \\
kegiatan pengabdian \\
kepada masyarakat
\end{tabular} & $\begin{array}{l}\text { Penentuan pelaksanaan } \\
\text { kegiatan pengabdian } \\
\text { kepada masyarakat }\end{array}$ \\
\hline 4. & $\begin{array}{l}\text { Pelatihan pemahaman } \\
\text { pengurus terhadap: } \\
\text { a Pencatatan dokumen } \\
\text { siklus kas } \\
\text { b. Pencatatan dokumen } \\
\text { siklus persediaan } \\
\text { c. Peccatatan dokumen } \\
\text { siklus piutang }\end{array}$ & $\begin{array}{l}\text { a. Dapat melakukan } \\
\text { pencatatan siklus kas } \\
\text { b. Dapat melakukan } \\
\text { pencatatan siklus } \\
\text { persediaan } \\
\text { c. Dapat melakukan } \\
\text { pectatatan siklus } \\
\text { piutang }\end{array}$ & $\begin{array}{l}\text { a. Pencatatan siklus kas } \\
\text { menunjukkan jumlah } \\
\text { yang benar } \\
\text { b. Pencatatan siklus } \\
\text { persediaan } \\
\text { menunjukkan jumlah } \\
\text { yang benar } \\
\text { c. Pencatatan siklus } \\
\text { piutang menumjukkan } \\
\text { jurrlah yang benar }\end{array}$ \\
\hline
\end{tabular}

Sasaran dari kegiatan pengabdian kepada masyarakat mengenai manajemen modal kerja yang baik ini ditujukukan pada pemilik dan pengurus start-up di kawasan UNNES yang berjumlah 25 orang.

Kegiatan pelatihan manajemen modal kerja yang baik bagi pemilik dan pengurus start-up di kawasan UNNES secara umum berjalan dengan lancar. Mitra pengabdian (HIPMI PT UNNES) membantu mempersiapkan tempat, sarana dan prasarana pelatihan, dan mengkoordinir serta mendelegasikan semua pengelola start-up untuk mengikuti kegiatan pelatihan dari awal kegiatan sampai dengan selesai.

Sebelum melakukan kegiatan pelatihan, pemateri memperkenalkan diri terlebih dahulu kemudian mencoba menggali pengetahuan tentang manajemen modal kerja. Pemateri mengajukan beberapa pertanyaan mengenai pengertian manajemen modal kerja, karakteristik manajemen modal kerja yang baik, pengelolaan modal kerja, dan perencanaan manajemen modal kerja untuk keberlangsungan usaha start-up. Setelah menggali pengetahuan, kemudian pemateri mulai memaparkan materi penguatan 
manajemen modal kerja untuk keberlangsungan start-up. Selama kegiatan pelatihan berlangsung, peserta tampak antusias dan memperhatikan isi materi pelatihan.

Kegiatan pemberian materi berlangsung selama kurang lebih 90 menit dan di akhir sesi pemateri memberikan kesempatan kepada peserta untuk mengajukan pertanyaan terkait materi yang telah disampaikan. Ada empat pertanyaan dari seluruh peserta pelatihan terkait isi materi. Setelah menjawab pertanyaan dari peserta, pemateri melakukan evaluasi terkait pemberian materi yang telah disampaikan dengan cara memberikan pertanyaan dan memberikan kesempatan kepada peserta untuk menjawab pertanyaan tersebut. Peserta yang mampu menjawab pertanyaan mendapatkan doorprize sebagai tanda apresiasi dan setelah itu kegiatan pelatihan dilanjutkan dengan praktik pembuatan dokumen siklus kas, siklus persediaan, dan siklus piutang. Kemudian, kegiatan pelatihan ditutup dengan kegiatan foto bersama antara pemateri, tim pengabdian kepada masyarakat UNNES, dan peserta pelatihan. Adapun kendala yang ditemukan selama proses kegiatan pelatihan adalah usia pengelola start-up relatih muda, sehingga perlu tenaga ekstra untuk membuat peserta tetap memperhatikan pemberian materi.

\section{PENUTUP}

\section{Simpulan}

Kesimpulan dari pelaksanaan pengabdian kepada masyarakat mengenai penguatan manajemen modal kerja yaitu sebagai berikut:

1. Kegiatan pengadian kepada masyarakat mengenai pelatihan manajemen modal kerja kepada pengelola start-up di kawasan UNNES telah terlaksana dengan baik.

2. Kegiatan pengabdian kepada masyarakat mengenai pelatihan manajemen modal kerja mendapatkan respon yang antusias dari peserta (pengelola start-up) di kawasan UNNES.
3. Dalam pelaksanaan pengabdian didapatkan empat pertanyaan dari peserta pelatihan terkait materi pelatihan dan peserta tersebut mengharapkan adanya keberlanjutan pelatihan kembali terkait pengelolaan modal kerja.

\section{Saran}

Saran dalam pelaksanaan pengabdian kepada masyarakat yaitu kegiatan pengabdian seperti ini dapat dilakukan secara rutin baik di lokasi yang sama maupun di lokasi yang berbeda dengan sasaran yang benarbenar membutuhkan pelatihan manajemen modal kerja terutama bagi pengelola start-up.

\section{DAFTAR PUSTAKA}

Arifin, Hasnul dan Tri Atmojo. (2016). Mendirikan Start-Up yang Diburu Angel Investor \& Big Van. Yogyakarta: Media Pressindo.

BPS. (2017). Laporan Bulanan Data Sosial Ekonomi, Edisi 81, Februari 2017. Katalog: 9199017. Diunduh pada laman: http://www.bps.go.id diakses pada 25 Februari 2017 pada pukul 06.45 WIB.

Chrismas, Edwardus. ( 20009$)$. Entrepreneurship Capital. Skripsi. FE. UI.

Horne, James C. Van dan John M. Wachowicz, Jr,. (2017). Fundamentals of Financial Management: Prinsipprinsip Manajemen Keuangan. Yogyakarta: Salemba Empat.

http://www.koran-jakarta.com/pertumbuhanekonomi-tak-ciptakan-lapangan-kerja/ diakses tanggal 2 Maret 2018

http://www.pojokbisnis.com/manajemen/ mengelola-sistem-modal-kerja diakses pada 02 Maret 2017.

Peraturan Rektor Universitas Negeri Semarang Nomor 27 Tahun 2012 
20 | EQUILIBRIUM, VOLUME 7, NOMOR 1, JANUARI 2019

Tentang Tata Kelola Kampus Berbasis Konservasi di Universitas Negeri Semarang.

Sari, Fransisca Desiana Pranata dan Sri Natasha Br Sitepu. (2016). Peran Faktor Internal dan Faktor Eksternal
Pada Keberlangsungan Start-Up Bisnis Kota Surabaya. Jurnal Manajemen Teori dan Terapan. 9 (1), 12-22.

UU No.12 tahun 2012 tentang Pendidikan Tinggi. 